\title{
Characteristics of the stress-strain state and structural changes in axisymmetric samples under sign-alternating deformation by free and constrained bending
}

\author{
G. I. Raab ${ }^{\dagger, 1}$, D. A. Aksenov ${ }^{1,2}$, R. N. Asfandiyarov ${ }^{1,2}$, A. G. Raab ${ }^{1}$, I. S. Kodirov ${ }^{1}$, M. Janeček ${ }^{3}$ \\ †giraab@mail.ru
}

${ }^{1}$ Ufa State Aviation Technical University, 12 K. Marx St., Ufa, 450077, Russia

${ }^{2}$ Institute of Molecule and Crystal Physics UFRC RAS, 151 Oktyabrya Av., Ufa, 450075, Russia

${ }^{3}$ CharlesUniversity, 5 Ovocný trh, Prague, 11636 , Czech Republic

\begin{abstract}
The paper presents the results of computer modeling and experimental studies of the parameters of the stress-strain state and structure of the material during deformation by the method of alternating multi-cycle bending of a long-length workpiece (bar, wire rod) around a rotating roller in free and constrained conditions. The material for the study was long-length rods of low alloyed bronze for electrical applications - the $\mathrm{Cu}-0.5 \% \mathrm{Cr}$ alloy. It was found that after 4 bending cycles with the workpiece turning through $90^{\circ}$ around the longitudinal axis, a gradient field of accumulated strain with maximum values in the peripheral region and minimum in the central region of the workpiece is formed in the workpiece before each subsequent processing cycle. Accordingly, the structural state also has a gradient distribution over the grain size. Constrained bending conditions provide a more uniform deformation field and lower average stresses in the deformation zone, which in turn leads to a smaller structural gradient in the cross section of the sample. After 4 cycles of free bending, a grain-subgrain structure with a minimum grain size of $7.0 \pm 0.5 \mu \mathrm{m}$ is formed in the surface layers of the workpiece, while in the central region, the grain size is $45 \pm 5 \mu \mathrm{m}$.
\end{abstract}

Keywords: alternating bending, bronze for electrical application, gradient structure, stress-strain state, finite element computer simulation.

\section{Introduction}

As a rule, cold or warm deformation, for example, rolling or drawing, is used to increase the complex of mechanical properties in metal materials. These processes lead to intense strain hardening, but also lead to a rapid exhaust of the plasticity limit and a decrease in the cross-sectional area of the initial workpieces [1-3]. One of the progressive methods of intensively increasing strength while maintaining somewhat higher ductile properties is the method of severe plastic deformation (SPD) - equal-channel angular pressing according to the Conform scheme (ECAP-Conform), which forms a homogeneous ultrafine-grained (UFG) structure in long-length metal materials without changing the cross-sectional area of the original workpieces [4-7]. The disadvantages of the ECAP method include problems of a technical nature, in particular, tribological and some others that hinder the implementation of such processes.

There is well known method of SPD referred to as the repeated corrugation and straightening (RCS) [8-13]. In the process of deformation processing by bending and subsequent straightening, refinement of the grain structure occurs. The deformation of long-length sheet workpieces is carried out with the help of profile rolls, and plates with a set of appropriate stamps.
The RCS method is most studied and often used in laboratory conditions to obtain UFG materials in the form of plates, however, it is characterized by a rather high laboriousness, since a large number (usually more than 16) of processing cycles is necessary and several types of equipment are required [14-19]. Despite this, deformation processing using the bending scheme can be used for mass production of UFG and NS materials, if one can manage to increase the process productivity.

In this regard, the aim of this work was to study the effect of multi-cycle sign-alternating bending of a long-length workpiece around a rotating roller for free and constrained conditions on its stress-strain state and structure. The study was carried out on the basis of data obtained using computer simulation in the DEFORM-3D software package and field experiments. The material for the study was long-length rods made of low alloy bronze for electrical applications.

\section{Material and experimental procedure}

As the study material, a $10 \times 10 \mathrm{~mm}$ square rod of the $\mathrm{Cu}-0.5 \% \mathrm{Cr}$ alloy was used in the state of a supersaturated solid solution obtained during high-temperature treatment at $1000^{\circ} \mathrm{C}$ and subsequent quenching in water. After quenching, a coarse-grained structure was formed with predominantly 
equiaxed grains with an average grain size of $180 \pm 18 \mu \mathrm{m}$. The microhardness of the alloy was $720 \pm 40 \mathrm{MPa}$, and the electrical conductivity was $52 \%$ IACS.

The study of the stress-strain state was carried out using finite element computer modeling in the Deform-3D software package. In the simulation, we used a $10 \times 10 \mathrm{~mm}$ square workpiece model with a length of about $200 \mathrm{~mm}$ during the first processing cycle, and in the subsequent ones, the accumulated strain, change in geometric parameters and temperature of the sample were taken into account.

The workpiece and tool models created in KOMPAS-3D were saved in the "stl" format.

The generated finite element mesh consisted of 50000 tetrahedra. The option to compensate for the volume of the workpiece model has been activated. The initial workpiece was a plastic body, and the tool was an absolutely rigid body. Tool models were not splitted into the finite element mesh.

The speed of rotation of the drive roller was chosen constant and equal to $60 \mathrm{rad} / \mathrm{sec}$.

The temperature of the sample in the first treatment cycle was taken equal to room temperature, i.e. $20^{\circ} \mathrm{C}$. The simulation was carried out taking into account the increase in the temperature of the workpiece from the thermal effect of plastic deformation (deformation heating). The temperature of the rollers was constant and equal to $20^{\circ} \mathrm{C}$. The Siebel friction factor $f=0.2$ was used. On the contact surfaces of the die-set, the impermeability condition was specified. The number of simulation steps for each processing cycle was more than 1000 .

Modeling and a physical experiment on deformation of the samples were carried out according to two bending schemes, namely, free (Fig. 1a) and constrained (Fig. 1b) ones. In the case of free bending, the sample (1) is pulled through rollers with a U-shaped engraving (2) mounted on the base (3) using an upgraded drawing mill. In case of constrained bending, the roller with a U-shaped engraving (2) is driven by a gear motor and pulls the workpiece (1) through the channel in the base (3). The number of deformation cycles $n=4$. After each cycle, the sample was rotated around the longitudinal axis by $90^{\circ}$.

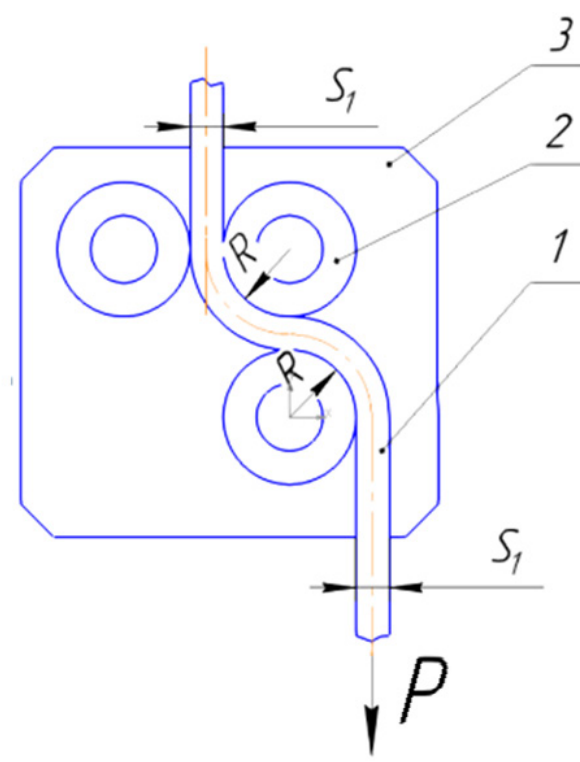

Structural studies were carried out at the mesoscale using a scanning electron microscope (SEM Jeol JSM-6390). As a result of mathematical modeling, it was shown that a heterogeneous deformation field is formed in the process of bending, and accordingly, the formation of a gradient structure is expected, therefore, the structure was studied in the peripheral and central regions of the sample.

Mechanical tensile tests were carried out on an Instron 5982 dynamometer. The electrical conductivity was measured by the eddy current method using the VE-27NTs instrument.

\section{Experimental results}

Fig. 2 shows the field map (a) and the graph (b) of the distribution of accumulated strain in the longitudinal and cross sections of the sample after 4 bending cycles in free conditions. It should be noted that when using free bending, the distribution of accumulated strain in the sample is heterogeneous with higher values in the peripheral regions of the workpiece and lower in the center. In this case, the strain distribution diagram in the cross section has a parabolic form, which indicates the gradient distribution of the strain in the cross section. When using the constrained bending scheme, the distribution of the accumulated strain in the sample is more uniform. This is expressed by the fact that the difference between the maximum and minimum value is smaller. For the free bending, for example, this value is 1.15 , and for the constrained one 0.68 .

An important parameter in the analysis of the stress state is the mean stresses, which are calculated by the formula [22]:

$$
\sigma_{\text {mean }}=\frac{1}{3} \cdot\left(\sigma_{1}+\sigma_{2}+\sigma_{3}\right)
$$

where $\sigma_{1}, \sigma_{2}, \sigma_{3}$ are the principal stresses. The mean stresses at the points of interest of the deformed body determine the rigidity of the stress state scheme and are components of the spherical stress tensor. If $\sigma_{\text {mean }}>0$, then tensile stresses prevail in the stress state scheme, and the scheme is considered to be rigid. If $\sigma_{\text {mean }}<0$, then compressive stresses prevail in the

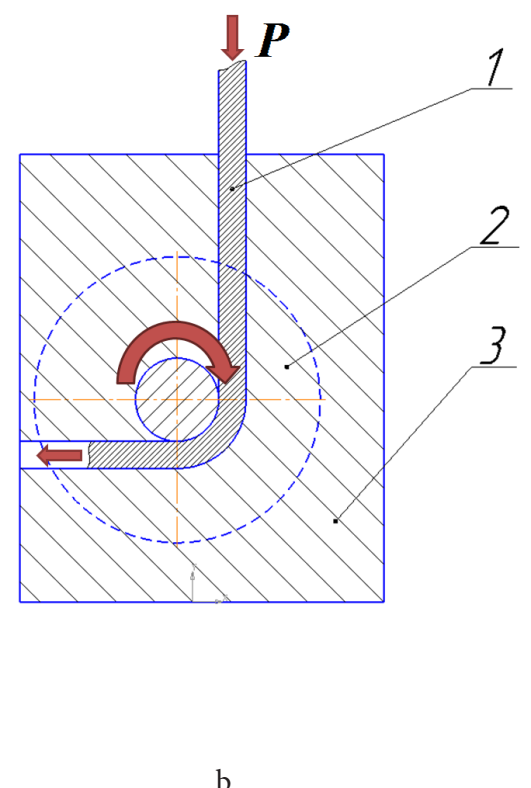

Fig. 1. Schemes of deformation by bending: free bending (a), constrained bending (b) ( 1 - workpiece, $2-$ roll, 3 - base). 
stress state scheme, and the scheme is considered to be soft The stress state significantly depends on the bending conditions. In case of free bending, tensile mean stresses reach values close to $150-160 \mathrm{MPa}$, while in constrained bending they do not exceed $85 \mathrm{MPa}$, i. e. two times less (Fig. 3). It can be noted that during continuous bending processing, both in the case of free and in the case of constrained conditions, cyclic changes in mean stresses are observed. For instance, in the inner layers of the workpiece compressive stresses are first observed during bending and then tensile stresses, while opposite behavior is observed in the outer layer. Thus, the stress state during a continuous bending process differs from static bending, when the inner layers at the bending radius are constantly under the action of compressive stresses, and the external, respectively, tensile ones.

Structural studies show that during free bending, a gradient type of structure is formed. As shown above by mathematical modeling, the gradient distribution of the accumulated strain depends on the bending conditions, which determines the gradient structure. With free bending in the central region of the sample, the strain is only $e=0.7$, while in the peripheral region it is $e=2$. The correlation between the data of mathematical modeling and structural changes can be seen in Fig. 4 a,b. A deformed refined structure is observed in the peripheral region of the sample. In the process of deformation, the simultaneous fragmentation of grains, growth twins, and twin boundaries occurs, which is consistent with the theory of fragmentation proposed by Rybin [23]. It should be noted that the strain and temperature for the fcc metal is not so great, therefore, it is impossible to reliably talk about fragmentation due to the formation of deformation origin twins [24]. The average grain size is $7.0 \pm 0.5 \mu \mathrm{m}$. A coarse-grained structure is observed in the central region of the sample. Rectilinear thin grain boundaries and residual twins of thermal origin, as well as slip bands in the bulk of grains, are observed. The average grain size in the central region of the sample is $45 \pm 5 \mu \mathrm{m}$.

Structural studies of the samples after 4 passes of constrained bending indicate that a more uniform structural state is formed in the sample. Fragmentation of the initial grains and their boundaries is observed. A mixed structure is formed in the peripheral region, however, elongated structural components can be distinguished, which at high magnifications can be identified as grains. In the central part of the sample, the structure elements are elongated. A large number of slip bands are observed. The average cross grain size in the peripheral layer and in the center is $15.0 \pm 0.8$ and $18 \pm 0.8 \mu \mathrm{m}$, respectively.

The electrical conductivity of the samples after free and constrained bending is almost the same and amounts $44 \pm 2$ and $46 \pm 2 \%$ IACS, respectively, i. e. became lower than the initial value equal to $52 \pm 2 \%$ IACS.

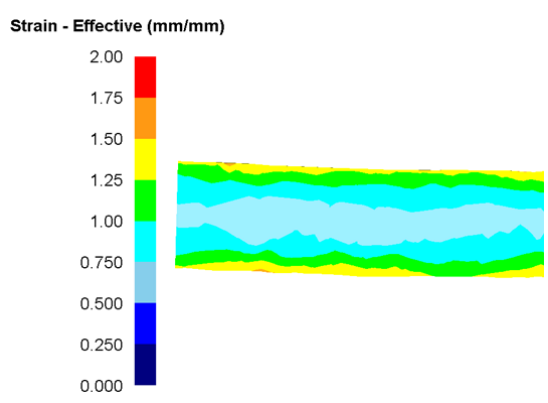

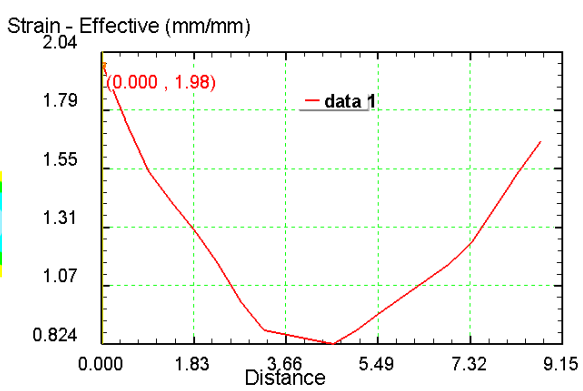

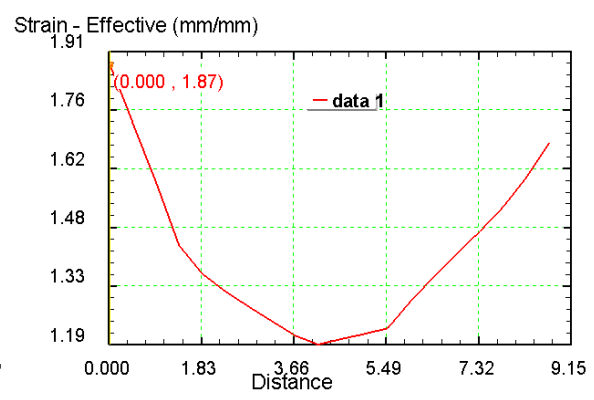

Fig. 2. (Color online) Deformed state: the field of the accumulated strain on the longitudinal section of the sample after 4 cycles of free bending (a), graph of the distribution of strain in the cross section after free bending (b), graph of the distribution of strain in the cross section after constrained bending (c).

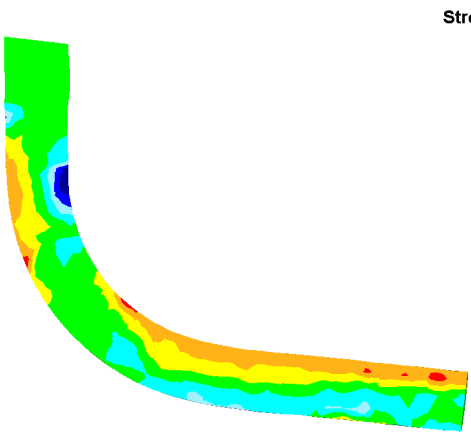

a
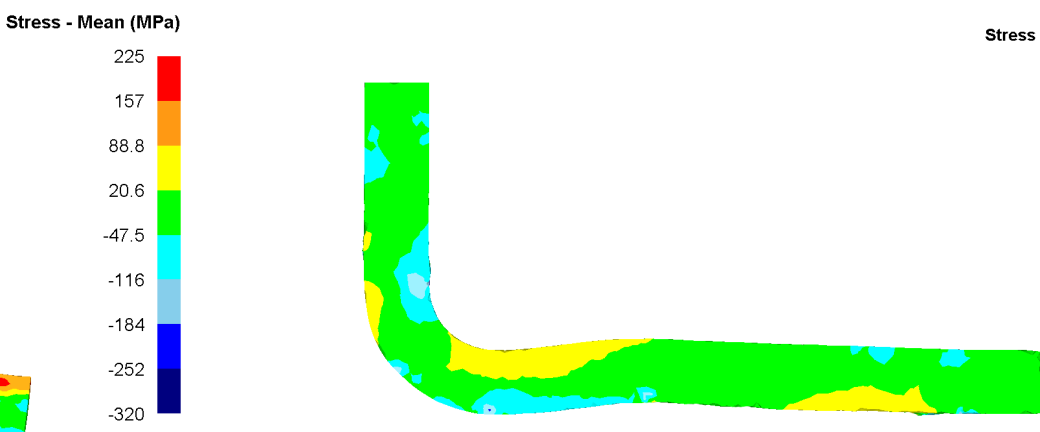

Stress - Mean (MPa)

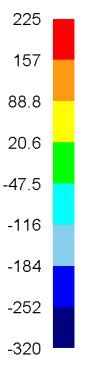

b

Fig. 3. (Color online) Stress state (longitudinal section): distribution of mean stress after free bending (a), distribution of mean stress after constrained bending (b). 


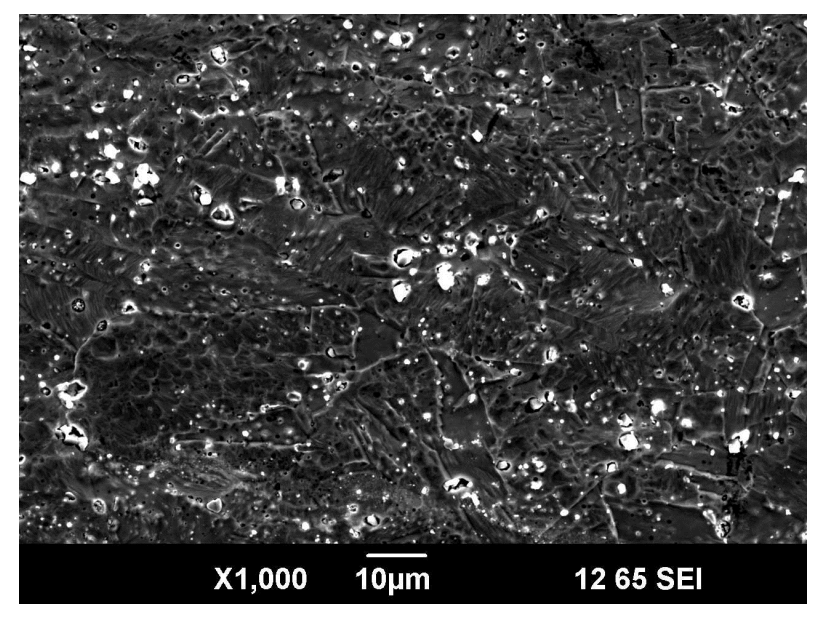

a

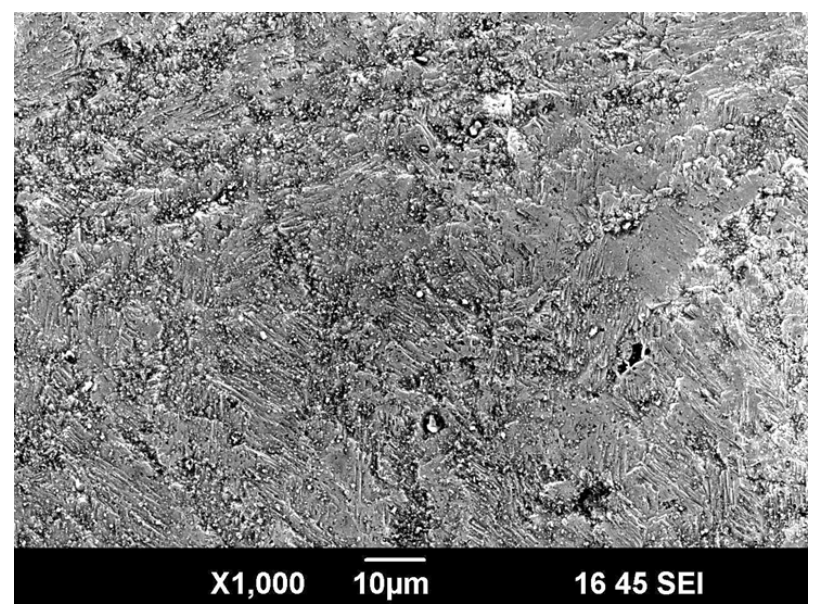

c

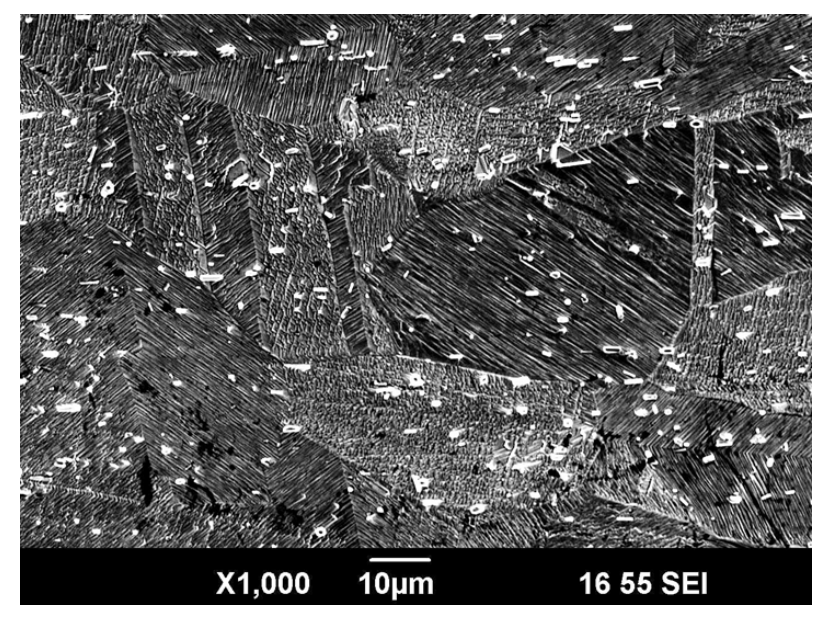

b

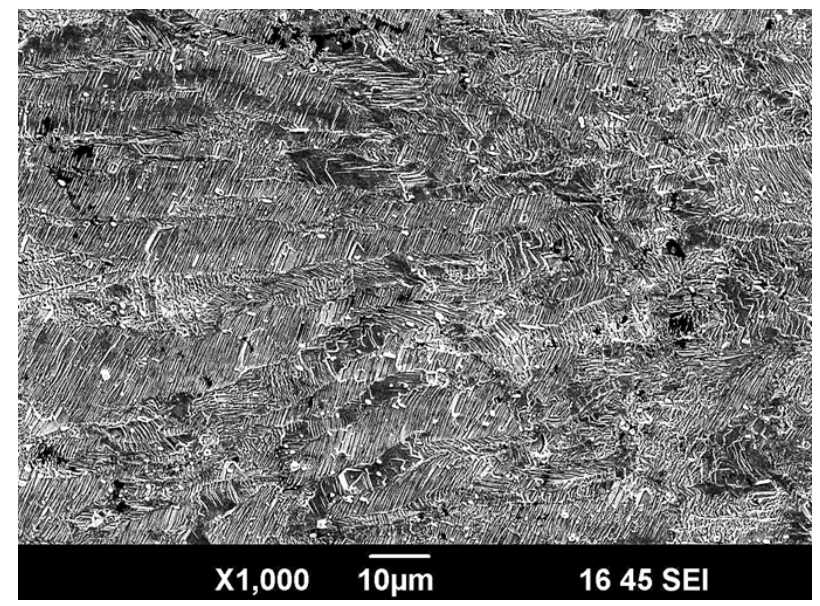

d

Fig. 4. Structure after free bending in the peripheral region (a) and center (b) and after constrained bending in the peripheral region (c) and center $(\mathrm{d})$.

\section{Discussion}

Thus, using computer simulation, it was found that after 4 bending cycles of the samples of the $\mathrm{Cu}-0.5 \% \mathrm{Cr}$ alloy with a rotation of $90^{\circ}$ around the longitudinal axis, a gradient field of accumulated strain is formed after each pass. The maximum strain values are noted in the surface layers of the workpiece (up to $e=2$ ), the minimum - in the central region $(e=0.7)$. With constrained bending, with other things being equal, the level of critical tensile stresses on the surface, which lead to fracture, decreases. The data of structural studies correlate with the stress-strain state data obtained by mathematical modeling, which is reflected in the gradient of the structure of the sample after free and constrained bending.

The structural analysis showed that after 4 cycles of free bending, the gradient of the structure is higher than after 4 cycles of constrained bending. The minimum grain size is $7.0 \pm 0 \mu \mathrm{m}$ in the surface layers of the workpiece and the maximum grain size is $45 \pm 5 \mu \mathrm{m}$ in the central region. The presence of slip traces in the form of bands in the surface layers indicates the presence of a substructure with an element size of less than $1 \mu \mathrm{m}$ [25]. In addition, undeformed residual growth twins are observed in the grain body of the central region. After constrained bending, a predominantly elongated structure forms; the difference between the average transverse grain size in the peripheral region and in the center is not so significant and does not exceed $3 \mu \mathrm{m}$. A decrease in the conductivity from $52 \pm 2 \%$ IACS to $44 \pm 2$ and $46 \pm 2 \%$ IACS for free and constrained bending, respectively, indicates that, under bending conditions, the supersaturated solution does not decompose or is not active.

\section{Conclusions}

Thus, it was found that four cycles of continuous free bending of long-length, low-alloyed copper samples lead to the formation of a gradient field of accumulated strain and, accordingly, to the formation of a gradient-type structure (range of grain size 7-45 $\mu \mathrm{m}$ ) with finer grains and substructure fragments up to $1 \mu \mathrm{m}$ in the peripheral layers of deformed samples. The use of constrained bending, other things being equal, leads to the formation of a more uniform deformed and structural states (range of grain size $15-18 \mu \mathrm{m}$, subgrains up to $1 \mu \mathrm{m}$ ). With constrained bending, the level of the most critical tensile mean stresses, relative to the free bending, decreases almost twice (from 160 to $85 \mathrm{MPa}$ ), which should favorably affect the workability of the $\mathrm{Cu}-0.5 \% \mathrm{Cr}$ alloy during bending. 
Acknowledgments. The authors are grateful for the support from the Ministry of Science and Higher Education of the Russian Federation under Grant agreement No. 14.586.21.0059 (UIN: RFMEFI58618X0059) and by the Czech Ministry of Education, Youth and Sports under the project LTARF18010.

\section{References}

1. R.Z. Valiev, A.P. Zhilyaev, T.G. Langdon. Bulk Nanostructured Materials: Fundamentals and Applications. John Wiley \& Sons, USA (2014) 456 p. Crossref

2. F.Z. Utyashev, G.I. Raab. Deformation Methods for the Fabrication and Processing of Ultrafine-Grained and Nanostructured Materials. Ufa, Gilem (2013) 376 p. (in Russian).

3. V.M. Segal, I. J. Beyerlein, C. N. Tome, V. N. Chuvil'deev, V.I. Kopylov. Fundamentals and Engineering of Severe Plastic Deformation. New York, Nova Science Publishers (2010) $542 \mathrm{p}$.

4. G. J. Raab, R.Z. Valiev, T.C. Lowe, Y.T. Zhu. Materials Science and Engineering: A. 382 (1-2), 30 (2004). Crossref

5. A. V. Polyakov, I. P. Semenova, G. I. Raab, V.D. Sitdikov, R. Z. Valiev. Rev. Adv. Mater. Sci. 31 (1), 78 (2012).

6. C. Xu, S. Schroeder, P.B. Berbon, T. G. Langdon. Acta Materialia. 58 (4), 1379 (2010). Crossref

7. V. Ayati, M.H. Parsa, H. Mirzadeh. Advanced Engineering Materials. 18 (2), 319 (2016). Crossref

8. J. Y. Huang, Y. T. Zhu, D. J. Alexander, X. Liao, T. C. Lowe, R. J. Asaro. Materials Science and Engineering A. 371, 35 (2004). Crossref

9. J.Y. Huang, Y.T.Zhu, H. Jiang, T.C. Lowe. Acta Mater. 49, 1497 (2001). Crossref

10. Y. Zhu, H. Jiang, J. Huang, T. Lowe. Metall Mater Trans A. 32, 1559 (2001). $\underline{\text { Crossref }}$
11. D. H. Shin, J. J. Park, Y. S. Kim, K. T. Park. Materials Science and Engineering A. 328 (1-2), 98 (2002). Crossref

12. A. Shirdel, A. Khajeh, M.M. Moshksar. Materials and Design. 31 (2), 946 (2010). Crossref

13. A. Krishnaiah, C. Uday, P. Venugopal. Scripta Materialia. 52(12), 1229 (2005). Crossref

14. J. Stobrawa, Z. Rdzawski, W. Głuchowski, W. Malec. Journal of Achievements in Materials and Manufacturing Engineering. 33 (2), 166 (2009).

15. J. P. Stobrawa, Z. M. Rdzawski, W. Głuchowski, W. Malec. Journal of Achievements in Materials and Manufacturing Engineering. 28 (2), 195 (2010).

16. W. Głuchowski, J.P. Stobrawa, Z. M. Rdzawski. Achieves of Material Science and Engineering. 47 (2), 103 (2011).

17. J. P. Stobrawa, Z. M. Rdzawski, W. Głuchowski, W. Malec. Journal of Achievements in Materials and Manufacturing Engineering. 56 (1), 171 (2011).

18. A. Mirsepasi, M.N. Ahmadabadi, M.H. Parsa, H.G. Nanesa, A.F. Dizaji. Materials Science and Engineering A. 551, 32 (2012). Crossref

19. Sh. Hashemipour, A. R. Eivani, H. R. Jafarian, M. Naseri, N. Park. Mater. Res. Express. 5, 126519 (2018). Crossref

20. Yu. F. Ivanov, V.V. Kovalenko, M.P. Ivakhin, et al. Fizicheskaya Mezomekhanika. 7 (3), 29 (2004). (in Russian)

21. K. Lu. Science. 345 (6203), 1455 (2014). Crossref

22. M. V. Storozhev. Teoriya obrabotki metallov davleniyem: uchebnik dlya vuzov (Ed.by M. V. Storozhev, E. A. Popov). 4th ed., Revised. and add. Moscow, Mashinostroyeniye, (1977) 423 p. (in Russian)

23. V. V. Rybin, N. Yu. Zolotorevsky, E. A. Ushanova. Journal of Technical Physics. 84 (12), 81 (2014). (in Russian)

24. R. Honikom. Plasticheskaya deformatsiya metallov. Moscow, Mir (1972) 408 p. (in Russian)

25. V.V. Rybin. Bol'shiye plasticheskiye deformatsii i razrusheniye metallov. Moscow, Metallurgy (1986) 224 p. (in Russian) 